\title{
Comparative evaluation of postpartum IUCD versus interval IUCD at a tertiary care centre in Allahabad, India
}

\author{
Urvashi Singh, Shubhangi Sonkar, Preeti Yadav*, Meena Dayal, \\ Veena Gupta, Somya Saxena
}

Department of Obstetrics and Gynecology, Moti Lal Nehru Medical College, Allahabad, Uttar Pradesh, India

Received: 04 February 2017

Revised: 04 March 2017

Accepted: 06 March 2017

*Correspondence:

Dr. Preeti Yadav,

E-mail: preeti_yadav3@yahoo.com

Copyright: (C) the author(s), publisher and licensee Medip Academy. This is an open-access article distributed under the terms of the Creative Commons Attribution Non-Commercial License, which permits unrestricted non-commercial use, distribution, and reproduction in any medium, provided the original work is properly cited.

\section{ABSTRACT}

Background: The use of $\mathrm{Cu} \mathrm{T}$ in postpartum period can provide long term and effective contraception and this study compares PPIUCD versus interval IUCD.

Methods: 300 women enrolled in the study were divided into two groups. Postpartum group-150; Postplacental or within 10 minutes/intracaesarean/within 48 hrs of delivery. Interval Group 150; after 6 weeks of delivery / postmenstrual. $\mathrm{Cu} \mathrm{T} \mathrm{380A} \mathrm{was} \mathrm{used} \mathrm{in} \mathrm{the} \mathrm{study.} \mathrm{Contraindication} \mathrm{for} \mathrm{PPIUCD} \mathrm{were} \mathrm{between} 48$ hrs and 6 wks postpartum, chorioaminionitis, PROM >18 hrs, unresolved PPH and puerperal sepsis. All were followed up for 6 months.

Results: The continuation rate at 6 months was $81.81 \%$ in interval group and $88.23 \%$ in postpartum group. Complications occurred in $15.33 \%$ cases after PPIUCD and in $19.33 \%$ cases after interval IUCD. Expulsion rate was significantly higher in PPIUCD as compared to interval insertions (6.96\% v/s 2.2\%; p value <0.05). Removal rate of IUCD was almost similar in both the groups (4\% in PPIUCD v/s $6.0 \%$ in interval).

Conclusions: PPIUCD is an effective, safe, convenient, low cost and long term method of postpartum contraception irrespective of the mode of delivery.

Keywords: $\mathrm{Cu}$ T, Interval IUCD, PPIUCD

\section{INTRODUCTION}

Nationally unplanned pregnancy rate is $21 \%$ of all pregnancies. ${ }^{1}$ In India $65 \%$ of women in the first year postpartum have an unmet need for family planning, out of which only $26 \%$ of woman are using any method of contraception. Hence, contraceptive counselling has become an integral part of antenatal and postpartum programme as pregnant and postpartum women are generally highly motivated towards controlling the fertility, either in spacing out there children or stopping their fertility altogether. Postpartum period is one of the sensitive time of woman's life when she is in contact with health care facility known as crisis oriented and when both mother and newborn need a special care. Postpartum contraceptive options are limited. Barrier contraceptives and progesterone only pills, both are user and compliance dependent methods and therefore have high failure rates. Traditionally, $\mathrm{Cu} \mathrm{T}$ insertion was limited to interval period. But now, recent studies on postpartum contraceptive methods have suggested the use of $\mathrm{Cu} \mathrm{T}$ in postpartum period which can provide long term and effective contraception with failure rate of $<1 \%$.

Percentage of institutional deliveries in India is $41 \% .^{2}$ As the number of institutional deliveries is increasing, postpartum $\mathrm{Cu} \mathrm{T}$ insertion can provide a unique opportunity to increase the contraceptive prevalence 
amongst women. In India, most women deliver their first baby at a very young age i.e. less than 20 years and complete their family at less than 30 years of age. But at an age of less than 30 years when their youngest child is less than 5 years of age, tubal ligation cannot be considered safe and effective because under- 5 mortality rates are quite high in developing countries like India. So, immediate postpartum IUCD (PPIUCD) insertion can be considered a safe and an effective method of contraception. In India only $2 \%$ of married women of reproductive age use IUCDs, though the last district level household and facility survey-3 survey (2007-2008) has shown an increase in the contraceptive use to $54 \%$. In 2010, PPIUCD service was introduced in facilities with high rate of deliveries. IUCD is usually inserted as an interval procedure that is six weeks after delivery or along with induced abortion.

PPIUCD insertion can be done postplacental that is within 10 mins of placental expulsion, intra caesarean at the time of caesarean section or within $48 \mathrm{hrs}$ of delivery. Inserting IUCD after placental delivery is safe. However, there is a continuing debate about the safety and efficacy of post placental IUCD insertion as there is theoretically higher risk of expulsion associated with involution of uterus and higher risk of infection due to lochia. Acceptance and continuation of IUCD can be increased by education and counselling.

The objective of the study was to compare safety, efficacy and complications of PPIUCD and interval IUCD insertion.

\section{METHODS}

The study was a prospective observational study done in 300 women attending OPD and IPD, in Department of Obstetrics and Gynecology, Swaroop Rani Hospital MLN Medical College, KNM Hospital and Dufferin Hospital, Allahabad, over a period of 12 months (Nov,2015Nov,2016). The subjects were divided into two groups. Postpartum group-150 women; postplacental or within 10 minutes/Intracaesarean/ Within $48 \mathrm{hrs}$ of delivery. Interval Group- 150 women; After 6 weeks of delivery/postmenstrual. Cu T 380A was used in the study.

Contraindications for PPIUCD were between 48 hours and 6 weeks post-partum, chorioaminionitis, prolonged rupture of membranes $>18$ hours, unresolved $\mathrm{PPH}$ and puerperal sepsis. There were three follow up visits-1st visit was at 6 weeks in postpartum group and after first menses or 6 weeks whichever is earlier in interval group, 2nd visit was after 3 months and 3 rd visit was at 6 months.

Women were explained to follow up as soon as possible if she noticed any of the following sign- foul smelling lochia, excessive bleeding and lower abdominal pain, any signs and symptoms of infection like fever, myalgia, and body ache etc and in case of expulsion. Out of total 300 women, 32 were lost to follow up at 6 months. The primary outcome measures recorded in follow up wereacceptability rate, visibility of strings and expulsion and incidence and spectrum of complications. The secondary outcome measures recorded were-reception of pain during IUCD insertion, patients level of satisfaction with treatment and recommendation of IUCD to others.

\section{Statistical analysis}

Chi square test, percentages and test of proportion.

\section{RESULTS}

The cases were divided into 2 groups according to type of IUCD insertion. The differences between both the groups, regarding age distribution, habitat, socioeconomic status, marital status, body mass index, parity, educational status, occupation, was found to be stastically insignificant (Table 1).

Table 1: Demographic variables

\begin{tabular}{|ll|l|}
\hline Variable & $\begin{array}{l}\text { Interval } \\
\text { Group }\end{array}$ & $\begin{array}{l}\text { Postpartum } \\
\text { Group }\end{array}$ \\
\hline AGE (years) & $27.6 \pm 2.8$ & $26.9 \pm 3.1$ \\
\hline Literate & $70.7 \%$ & $80 \%$ \\
\hline Housewives & $52.78 \%$ & $51.51 \%$ \\
\hline Married & $61.29 \%$ & $54.54 \%$ \\
\hline Urban & $77.41 \%$ & $78.78 \%$ \\
\hline
\end{tabular}

No perforation was encountered during the procedure, either in interval or in postpartum cases. Maximum number of women, $81.3 \%$ in interval group and $86.7 \%$ in postpartum group were satisfied with copper $\mathrm{T}$ at six months of follow up (Table 2).

The women were classified as 'partially satisfied' when they experienced some complication, but preferred to continue with the use of copper $\mathrm{T}$ due to its contraceptive benefits. The continuation rate in our study was $81.81 \%$ in interval group and $88.23 \%$ in postpartum group (Table 3).

Complications occurred in $15.33 \%$ (23) cases after PPIUCD, while after interval insertion complications occurred in $19.33 \%$ (29) cases. Most common complication after PPIUCD insertion was expulsion , while after interval insertion bleeding was most common complication . Expulsion rate was significantly higher in PPIUCD as compared to interval insertions $(6.96 \% \mathrm{v} / \mathrm{s}$ $2.2 \%$; p value $<0.05)$ (Table 4$)$.

Cause of removal was mainly bleeding ( 8 cases, $88.89 \%$ ) in interval IUCD group which was significantly higher as compared to PPIUCD group $(41.2 \%)$. IUCDs were removed because of social factors in most of women $(58.8 \%)$ with PPIUCD (Table 5). 
Table 2: Satisfactory status of women.

\begin{tabular}{|llllll|}
\hline & & \multicolumn{2}{c}{ Interval group } & \multicolumn{3}{c|}{ Postpartum group } \\
\cline { 2 - 6 } & No & $\mathbf{\%}$ & No & \% \\
\hline \multirow{3}{*}{ Follow Up1 } & Not satisfied & 7 & 5.07 & 9 & 6.2 \\
\cline { 2 - 6 } & Satisfied & 122 & 88.4 & 133 & 92.3 \\
\cline { 2 - 6 } & Partially satisfied & 9 & 6.5 & 2 & 1.4 \\
\hline \multirow{3}{*}{ Follow Up 2 } & N & 138 & & 144 & \\
& Not satisfied & 6 & 4.4 & 6 & 4.3 \\
\cline { 2 - 6 } & Satisfied & 126 & 92.5 & 130 & 92.9 \\
\cline { 2 - 6 } & Partially satisfied & 4 & 2.9 & 4 & 2.9 \\
\hline \multirow{2}{*}{ Follow Up 3 } & N & 136 & & 140 & \\
& Not satisfied & 6 & 4.5 & 6 & 4.4 \\
\hline & Satisfied & 122 & 92.4 & 130 & 95.6 \\
\hline & Partially satisfied & 4 & 3 & 0 & .0 \\
\hline
\end{tabular}

Table 3: Continuation rate at 6 months.

\begin{tabular}{|cccccc|}
\hline At 6 Months & $\begin{array}{c}\text { Women } \\
\text { followed Up }\end{array}$ & $\begin{array}{c}\text { Total women } \\
\text { with expulsion }\end{array}$ & $\begin{array}{c}\text { women who got } \\
\text { Cu-T removed }\end{array}$ & $\begin{array}{c}\text { Women who } \\
\text { continued }\end{array}$ & Percentage \\
\hline Interval group & 132 & 15 & 9 & 108 & 81.81 \\
\hline Postpartum group & 136 & 10 & 6 & 120 & 88.23 \\
\hline
\end{tabular}

Table 4: Complications After IUCD Insertion.

\begin{tabular}{|c|c|c|c|c|}
\hline \multirow{2}{*}{$\begin{array}{l}\text { Clinical } \\
\text { Presentation at } \\
\text { follow up }\end{array}$} & \multicolumn{2}{|c|}{$\begin{array}{l}\text { Interval } \\
\text { Group }\end{array}$} & \multicolumn{2}{|c|}{$\begin{array}{l}\text { Postpartum } \\
\text { Group }\end{array}$} \\
\hline & No. & $\%$ & No. & $\%$ \\
\hline Bleeding $\mathrm{P} / \mathrm{V}$ & 11 & 7.9 & 4 & 2.7 \\
\hline Discharge $\mathrm{P} / \mathrm{V}$ & 8 & 5.8 & 4 & 2.7 \\
\hline $\begin{array}{l}\text { Pain in Lower } \\
\text { Abdomen }\end{array}$ & 4 & 2.9 & 2 & 1.3 \\
\hline PID & 0 & 0 & 0 & 0 \\
\hline Missing Thread & 3 & 2.2 & 3 & 2.2 \\
\hline Expulsion & 3 & 2.2 & 10 & 6.96 \\
\hline Total & 29 & 19.33 & 23 & 15.33 \\
\hline
\end{tabular}

Table 5: Causes of removal of IUCD over a period of 6 months.

\begin{tabular}{|lllll|}
\hline \multirow{2}{*}{$\begin{array}{l}\text { Cause of } \\
\text { Removal }\end{array}$} & \multicolumn{3}{c}{ Interval Group } & $\begin{array}{l}\text { Postpartum } \\
\text { Group }\end{array}$ \\
& No. & \% & No. & $\%$ \\
\hline Bleeding P/V & 8 & 88.89 & 1 & 41.2 \\
\hline Discharge P/V & 0 & 0 & 0 & 0 \\
\hline PID/Pain & 1 & 11.11 & 0 & 0 \\
\hline For Conception & 0 & 0 & 0 & 0 \\
\hline $\begin{array}{l}\text { Other } \\
\begin{array}{l}\text { Contraceptive } \\
\text { Method }\end{array}\end{array}$ & 0 & 0 & 0 & 0 \\
\hline Social Factor & 0 & 0 & 5 & 58.8 \\
\hline Total & $\mathbf{9}$ & $\mathbf{1 0 0}$ & $\mathbf{6}$ & $\mathbf{1 0 0}$ \\
\hline
\end{tabular}

\section{DISCUSSION}

Postpartum period is the time when women are highly receptive and motivated to accept family planning method. Also, women are vulnerable to unintended pregnancy because contraceptive options are limited in breast feeding women. Since ovulation is highly unpredictable in non-breast feeding and partially breastfeeding women, couples often underestimate the likelihood of pregnancy. Postpartum women often want a method that provide long term temporary contraception, but doesn't want permanent sterilization. This emphasizes the need to provide a contraceptive method in the immediate postpartum period, in order to avoid unplanned pregnancies and the morbidity associated with subsequent abortion. Postpartum insertion of IUCD provides long term and effective contraception immediately after delivery without significant additional complications and does not require constant supervision. Women who wish to use contraceptive method 6 weeks after delivery, often do not return and subsequently experience an unintended pregnancy. Thus, insertion of copper $\mathrm{T}$ immediately after delivery can help in preventing unplanned pregnancy and subsequent safe or unsafe abortions.

In present study, the mean age of women in postpartum group was 27.6 \pm 2.8 years and interval group was $27.13 \pm 3.1$ years, thus both groups are matched to age and constitute a younger age group. Maximum number of women in either interval $(73.3 \%)$ or postpartum group 
(80\%) belonged to age group of 25-30 years, suggesting that women of younger age group are more easily counselled as even they are looking for an effective method of contraception after child birth. Other studies also showed similar results like the mean age of women in post placental copper $\mathrm{T}$ insertion group was 24.5 years in the study done by $\mathrm{Xu}$ et al and 23.4 years in the study conducted by Morrison et al, 24.7 years in the study conducted by Celen et al and 23.12 \pm 2.42 years in the study by Singal $\mathrm{S}$ et al in, all of them being a young age group. ${ }^{3-6}$

In present study, no case of perforation occurred in interval or postpartum group. The possible reason for low perforation rate in post placental insertion is due to thick uterine wall and inserter's expertise. In accordance to our study, no perforations were reported in post placental IUD insertion in the studies done by Kapp et al and Gupta $\mathrm{G}$ et al which matches our study. ${ }^{7,8}$

In present study, the number of women who were satisfied with the use of $\mathrm{Cu} \mathrm{T}$ as a contraceptive method at 1 st, 2nd and 3rd follow up visit in interval delivery and postpartum delivery were $122(88.4 \%), 126(92.5 \%)$ and $122(92.4 \%)$ and $133(92.3 \%), 130(92.9 \%)$ and 130 $(95.6 \%)$ respectively. This emphasizes that the mode of delivery is not affecting the satisfaction level of the women . This is similar to study conducted by Gupta G et al with percentage satisfaction among users after 6 weeks-91.7\%, 3 months-92.9\%, and 6 months- $-95.6 \%{ }^{8}$

The present study showed continuation rates of about $88.23 \%$ for PPIUCD users over a follow up period of 6 months. Celen et al also showed continuation rates of $87.6 \%$ for PPIUCD at 6 months' interval. ${ }^{5}$ On comparing, PPIUCD with Interval IUCD, slightly higher continuation rates were obtained for PPIUCD group (87.6\%) than interval group $(81.81 \%)$ in present study. Although slight difference exists between the two groups but the difference was not statistically significant $(\mathrm{p}=0.49)$.

While comparing PPIUCD with interval IUCD, the cumulative rate of complications was $15.33 \%$ and $19.33 \%$ in PPIUCD group and interval IUCD group respectively and although complications were less in PPIUCD group but the difference was statistically insignificant. This was in accordance with the study Eroglu et al where the rates of complications did not differ significantly between the two groups. ${ }^{9}$

In our study, expulsion rate after PPIUCD was $6.96 \%$ which is in accordance with study of Eroglu et al. ${ }^{9}$ The rate of expulsion in interval IUCD group in this study was $2.2 \%$ which was significantly lower $(p<0.05)$ as compared to PPIUCD group. In study by Shukla et al, the cumulative expulsion rate at the end of 6 months was 10.68 per cent. ${ }^{10}$ Bonilla Rosales $\mathrm{F}$ et al in their study found expulsion rate of $16 \%$ and $2 \%$ for PPIUCD and interval IUCD respectively. ${ }^{11}$ Expulsion was the most common complication in the PPIUCD group, $6.96 \%$ cases (2.2\% in interval group). However, Bleeding was the most common complication in the interval group, $7.9 \%$ (2.7\% in PPIUCD group).

No case of PID was reported in present study. EL Beltagy et al ${ }^{12}$ also reported no increase in the incidence of PID after immediate postpartum IUCD insertion. Tatum et al reported no clinically apparent pelvic infection after post placental IUD insertion at 6 months follow up. ${ }^{13}$ However, Eroglu et al reported genital infection in $1.3 \%$ women in post placental copper $\mathrm{T} 380 \mathrm{~A}$ insertion group and $3.8 \%$ of women in interval group. ${ }^{9}$

In present study, rate of removal over 6 months follow up after PPIUCD insertion was $4 \%$. However, rate of removal in interval group was $6 \%$, whereas it was statistically insignificant $(\mathrm{p}=0.95)$. The results of studies carried out by Thiery et al, Tatum et al and Celen et al are similar to the result of present study. ${ }^{5,13,14}$ Most common medical reason for PPIUCD removal in our study was bleeding which account for removal in $23.5 \%$ cases.

\section{CONCLUSION}

Thus it was concluded from the present study that insertion of $\mathrm{Cu} \mathrm{T}$ immediately following delivery i.e. postplacental is an effective, safe, convenient, low cost and long term method of postpartum contraception irrespective of the mode of delivery. Increased institutional deliveries in India provides an opportunity for offering family planning services to the women, who have just delivered at health facilities and want to prevent unintended pregnancies or delay having more children. Although, the rate of expulsion of copper $\mathrm{T}$ is high in postpartum period when compared to interval insertion but it can be reduced by ensuring correct technique of insertion and correct timing of insertion i.e. within 10 minutes of expulsion of placenta.

The risk of other complications like bleeding, pain in lower abdomen and infection were relatively less in both the groups. The removal rate for bleeding and/or pain was found to be lower in either group. No case of perforation and pregnancy occurred in the entire study. The incidence of missing threads was higher in PPIUCD group which was probably due to coiling of long threads of copper $\mathrm{T}$ inside the uterine cavity. The 6 months' continuation rate was quite good in PPIUCD group. As, there is an increased risk of expulsion, by which questions regarding its efficacy are made. But, its benefits outweigh the risks. So this method should be popularised across the country as an option to all women, undergoing institutional deliveries, in tertiary health centers irrespective of the mode of delivery.

\section{Funding: No funding sources}

Conflict of interest: None declared

Ethical approval: The study was approved by the Institutional Ethics Committee 


\section{REFERENCE}

1. Santhya KG. Changing Family Planning Scenario in India. Regional Health Forum WHO South-East Asia Region http://www.searo.who.int/en/Section1243/ Section 1310 / Section 1343 / Section1344/Section1836/Section1838.html ， 2004 [cited 2012 May 4].;8(1).

2. India. National Family Health Survey-3. 2005-06 Available from: Government of India, Ministry of Health and family welfare Web site: www.nfhsindia.org/factsheet.html. cited 2012 May 3.

3. Xu JX, Rivera R, Dunson TR, Zhuang LQ, Yang XL and Ma GT. A comparative study of two techniques used in immediate post placental insertion (IPPI) of the Copper T 380A IUD in Shanghai, People's Republic of China. Contraception 1996;54(1):33-8.

4. Morrison C, Waszak C, Katz K, Diabate F, Mate EM. Clinical outcomes of two early postpartum IUD insertion programs in Africa. Contraception. 1996;53(1):17-21.

5. Celen S, Moroy P, Sucak A, Aktulay A, Danisman N. Clinical outcomes of early post placental insertion of intrauterine contraceptive devices. Contraception. 2004;69:279-82.

6. Singal S, Bharti R, Dewan R, Divya, Dabral A, Batra A, Sharma M, Mittal P: Clinical Outcome of Postplacental Copper T 380A Insertion in Women Delivering by Caesarean: J Clin Diagn Res. 2014;8(9):OC01-4.

7. Kapp N, Curtis KM. Intrauterine device insertion during the postpartum period: a systematic review. Contraception. 2009;80(4):327-36.

8. Gupta G, Goyal R, Kadam VK, Sharma P1. The Clinical Outcome of Post Placental Copper-T-380A Insertion with Long Placental Forceps (Kelly's Forceps) After Normal Vaginal Delivery and Caesarean Section: J Obstet Gynaecol India. 2015;65(6):386-8.
9. Eroglu K, Akkuzu G, Vural G, Dilbaz B, Akin A, Taskin L, et al. Comparison of efficacy and complications of IUD insertion in immediate postplacental/early postpartum period with interval period: 1 year follow-up. Contraception. 2006;74:376-81.

10. Shukla M, Qureshi S, Chandravati: Post placental intrauterine device insertion-a five year experience at a tertiary care centre in north India. Indian $\mathbf{J}$ Med Res. 2012;136:432-5.

11. Bonilla Rosales F, Aguilar Zamudio ME, Cazares Montero ML, Hernandez Ortiz ME, Luna Ruiz MA. Factors for expulsion of intrauterine device TCu380A applied immediately postpartum and after a delayed period. Rev Méd Inst Mex Seguro Soc. 2005;43:5-10.

12. El Beltagy NS, Darwish EA, Kasem MS, Hefila NM. Comparison between cupper T380 Iud and multi load 375 Iud in early post-partum insertion. Middle East Fertility Society J. 2010;16:143-8.

13. Tatum HJ, Beltran RS, Ramos R, Van KH, Sivin I, Schmidt FH. Immediate post placental insertion of GYNE-T 380 and GYNE-T 380 Postpartum intrauterine contraceptive devices: Randomized study. Am J Obstet and Gynecol. 1996;175(5):12315.

14. Thiery M, Van DPH, Delbeke L, Van KH. Comparative performance of two copper-wired IUDs (ML Cu 250 and $\mathrm{T} \mathrm{Cu}$ 200). Immediate postpartum and interval insertion. Contracept Deliv Sys. 1980;1(1):27-35.

Cite this article as: Singh $\mathrm{U}$, Sonkar S, Yadav $\mathrm{P}$, Dayal M ,Gupta V, Saxena S . Comparative evaluation of postpartum IUCD versus interval IUCD at a tertiary care centre in Allahabad. Int J Reprod Contracept Obstet Gynecol 2017;6:1534-8. 